

Original Research Article

\title{
A study on community perception and risk reduction practices for dengue and malaria in field practice area of RHTC of JNUIMSRC, Jaipur- A cross-sectional study
}

\author{
Surendra Mohan Mathur ${ }^{1}$, Brajesh Kumar ${ }^{2, *}$, Rekha Mathur ${ }^{3}$, Ranjit K Jha ${ }^{1}$ \\ ${ }^{1}$ Dept. of Community Medicine, JNU Institute for Medical Sciences \& Research Centre, Jaipur, Rajasthan, India \\ ${ }^{2}$ Dept. of Community Medicine, S N Medical College, Agra, Uttar Pradesh, India \\ ${ }^{3}$ Dept. of Medical Health and Family Welfare, Government of Rajasthan, Jaipur, Rajasthan, India
}

\section{A R T I C L E I N F O}

Article history:

Received 18-09-2020

Accepted 08-10-2020

Available online 08-01-2021

\section{Keywords:}

Perception

Knowledge

Attitude

Behaviour

\begin{abstract}
A B S T R A C T
Introduction: Globally, Vector Borne Diseases (VBDs) account for $17 \%$ of infectious disease burden Among VBDs, malaria and dengue are major public health problems due to their endemic nature and at times presenting outbreaks, and socioeconomic effects of them. A recent estimate indicates 390 million dengue infections per year, of which 96 manifest clinically with any severity of disease. The number of reported cases have increased from 2.2 million in 2010 to 3.2 million in 2015. India, being the highest burden country in South East Asian region, showed a declining trend in malaria incidence in recent years and is now poised to continue its stride toward achieving malaria elimination target by 2030 .

Materials and Methods: From November 2019 to February 2020. People residing in field practice area of RHTC, JNUIMSRC, village Sindoli Jaipur. The study was done by a pre-designed, pre -tested, semistructured interview schedule.

Discussion: In present study $88.4 \%$ heard about Malaria and Dengue, $46.37 \%$ were knowing all symptoms of these diseases, $83.69 \%$ know that it is transmitted by mosquito bite and $79.71 \%$ knew that water is their breeding site. $82.24 \%$ knew that water clogging is major cause of breeding. $65.57 \%$ believed that they are at risk of these diseases. $80.07 \%$ believed that clearing of water containers weekly will prevent breeding, $44.92 \%$ believe control activities a joint responsibility and $55.43 \%$ believe that public health persons should be allowed to inspect and spray. $54.71 \%$ believe sleeping under net prevent from malaria and Dengue. $83.69 \%$ practice environmental cleanliness to prevent these diseases. $37.68 \%$ respondent were drying their coolers when it was empty after use. $87.31 \%$ were using covered overhead tanks. $61.95 \%$ used to through coconut shells, egg shells and empty containers and used household water in discriminately.

Conclusion: Rapid unplanned urbanization with the growth of substandard housing conditions, poor sanitation, and other anthropogenic environmental changes has made rural areas and urban slums more vulnerable to these diseases and unavailability of effective vaccines, resistance to anti-malarial and antidengue medicines has further worsen to the situation. For this problem public health experts require a deeper insights into existing community perceptions and practices and thereby helps in identifying the attributes that influence the community in adopting healthy practices and responsive behaviors, as regard Malaria and Dengue.
\end{abstract}

(C) This is an open access article distributed under the terms of the Creative Commons Attribution License (https://creativecommons.org/licenses/by/4.0/) which permits unrestricted use, distribution, and reproduction in any medium, provided the original author and source are credited.

\footnotetext{
* Corresponding author.

E-mail address: brajeshchahar201@gmail.com (B. Kumar).
}

\section{Introduction}

Globally, Vector Borne Diseases (VBDs) account for $17 \%$ of infectious disease burden. ${ }^{1}$ Among VBDs, malaria and dengue are major public health problems due to their 
endemic nature and at times presenting outbreaks, and socioeconomic effects of them. In 2017, nearly half of the world's population was at risk of malaria with an estimated 219 million cases $^{2}$ whereas, Dengue, a neglected tropical disease is endemic in more than 100 countries with over two-fifths of world's population at risk. ${ }^{3}$ About 3.9 billion people in 128 countries are at risk of infection with dengue viruses. A recent estimate indicates 390 million dengue infections per year, of which 96 manifest clinically with any severity of disease. The number of reported cases have increased from 2.2 million in 2010 to 3.2 million in 2015. India, being the highest burden country in South East Asian region, showed a declining trend in malaria incidence in recent years and is now poised to continue its stride toward achieving malaria elimination target by $2030 .{ }^{4}$ The year 2016 was characterized by large dengue outbreaks worldwide. In 2015, Delhi, recorded its worst outbreak since 2006 with over 15,000 cases. According to the latest estimates, there were 216 million cases of malaria in 2016 with 445,000 deaths. Between year 2010 and 2016, malaria incidence among population at risk decreased by 18 per cent globally; during the same period malaria mortality rates among population at risk decreased by $32 \%$ about 91 per cent of malaria cases and 99 per cent of deaths due to malaria is reported from North-eastern states, Chhattisgarh Jharkhand, Madhya Pradesh, Odisha, Andhra Pradesh, Maharashtra, Gujarat, Rajasthan, West Bengal and Karnataka. The malaria incidence and deaths due to malaria have reduced significantly in recent years. Increase in number of P. Falciparum infection has increased the mortality caused by Malaria considerably, especially in eastern area of India. However, dengue is endemic in all 29 states and 6 UTs in India, and has witnessed a rapid increase in incidence over the past 50 years. Despite ongoing efforts and surveillance activities, West Bengal reported recurrent outbreaks in recent past and had maximum reported cases among all states in 2016. ${ }^{5}$ Thus India is facing a great public health problem in the form of Malaria and Dengue.

\section{Objectives}

1. To determine the socio-demographic profile of people living in the field practice area of RHTC, JNUIMSRC, village. Sindoli, Jaipur, Rajasthan, and

2. To determine the perception and risk reduction practices, attitude and knowledge of malaria and dengue among them.

\section{Materials and Methods}

\subsection{Study design}

Cross sectional study.

\subsection{Study duration}

From November 2019 to February 2020.

\subsection{Study population}

People residing in field practice area of RHTC, JNUIMSRC, village Sindoli Jaipur.

\subsection{Sampling method}

Purposive sampling method was followed.

\subsection{Sample size calculation}

A previous community based cross sectional study in Chetla, Kolkata, by Sahoo et al. ${ }^{6,7}$ reported that $97.9 \%$ of study participants had awareness that malaria is transmitted by mosquito followed by dengue $(90.9 \%)$. The sample size was estimated based on the reported awareness on dengue (0.9) and considering confidence interval of 95\% with Z1$\alpha=\mathrm{Z} 0.95=1.96$ and absolute error (L) of $5 \%$. As multistage sampling was done, a design effect of two was used to calculate the sample

Sample size $=N=\frac{Z^{2} p *(1-p)}{\varepsilon^{2}}$

Where, $p$ : Prevalence rate of malaria \& Dengue is around $90.9 \%$ in India $(\mathrm{p}=0.909)$.

$Z$ : Inverse normal probability $=1.96$

$\varepsilon$ : Margin of error, i.e. 0.05

By using the above formula, the sample is 138

Design effect, Sample size $=$ Nx2 $=138 \times 2=276$.

\subsection{Study tools}

The study was done by a pre- designed, pre -tested, semistructured interview schedule.

\subsection{Inclusion criteria}

Consenting adult family member ( $\geq 15$ years) among residents (residing for $>2$ years) in selected field practice area were interviewed, preferably the head.

\subsection{Exclusion criteria}

Those who were not willing to participate in the study and were less than 15 and more than 60 years of age were excluded from present study. Besides those who could not be contacted in spite of two visits due to their engagement in other official / personal works, were also excluded from present study.

\subsection{Ethical approval and consent}

Study was carried out after taking due permission from Institutional Ethics Committee JNUIMSRC and after taking informed consent from participants. 
Table 1: Socio-demographic distribution of respondents

\begin{tabular}{|c|c|c|c|}
\hline \multirow{3}{*}{ 1. Gender } & Variables & Numbers & Percentage \\
\hline & Male & 184 & 66.66 \\
\hline & Female & 92 & 33.33 \\
\hline \multirow{4}{*}{ 2. Age Groups } & $15-25 \mathrm{yrs}$ & 27 & 9.78 \\
\hline & $26-35 \mathrm{yrs}$ & 42 & 15.21 \\
\hline & $36-45$ yrs & 61 & 22.10 \\
\hline & $46-60$ yrs. & 46 & 16.66 \\
\hline \multirow{3}{*}{ 3. Religion } & Hindu & 269 & 97.46 \\
\hline & Muslim & 07 & 02.53 \\
\hline & Others & 00 & 00 \\
\hline \multirow{4}{*}{ 4. Education } & Illiterate & 121 & 43.85 \\
\hline & Primary & 77 & 27.89 \\
\hline & Middle & 51 & 18.47 \\
\hline & Hr Sec and above & 27 & 09.78 \\
\hline \multirow{3}{*}{ 5. Occupation } & Farmer & 221 & 80.07 \\
\hline & Service & 39 & 14.13 \\
\hline & Business & 16 & 05.79 \\
\hline \multirow{3}{*}{ 6. Housing } & Pucca & 76 & 27.53 \\
\hline & Semi-pucca & 151 & 54.71 \\
\hline & Katcha & 49 & 17.75 \\
\hline \multirow{2}{*}{ 7. Socio-economic status } & BPL & 39 & 14.13 \\
\hline & Others & 237 & 85.86 \\
\hline
\end{tabular}

Table 2: Distribution of knowledge of respondents about dengue and malaria

\begin{tabular}{|c|c|c|c|}
\hline \multirow{4}{*}{ 1. Heard about Disease } & Variables & Numbers & Percentage \\
\hline & Yes & 243 & 88.04 \\
\hline & No. & 33 & 11.95 \\
\hline & Fever with chills, rigor & 107 & 38.76 \\
\hline \multirow{2}{*}{ 2. Symptom of Dis. } & Headache / Bodyache & 27 & 09.78 \\
\hline & Vomiting, Diarrhoea & 14 & 05.07 \\
\hline \multirow{5}{*}{ 3. How Dis. transmits } & All of above & 128 & 46.37 \\
\hline & By mosquito bite & 231 & 83.69 \\
\hline & $\begin{array}{l}\text { Ingestion of contaminated } \\
\text { food, and water }\end{array}$ & 30 & 10.86 \\
\hline & Polluted air & 11 & 03.98 \\
\hline & Direct contact & 4 & 01.44 \\
\hline \multirow{5}{*}{ 4. Where mosquito breed. } & Water & 220 & 79.71 \\
\hline & Soil & 9 & 03.26 \\
\hline & Garbage & 21 & 07.60 \\
\hline & Plants & 7 & 02.53 \\
\hline & Do not know & 19 & 06.88 \\
\hline \multirow{2}{*}{$\begin{array}{l}\text { 5. Can you identify mosquito } \\
\text { responsible }\end{array}$} & Yes & 21 & 07.60 \\
\hline & No & 255 & 92.39 \\
\hline \multirow{3}{*}{$\begin{array}{l}\text { 6. Is water logging is major } \\
\text { cause of breeding }\end{array}$} & Yes & 227 & 82.24 \\
\hline & No & 11 & 03.98 \\
\hline & Do not know & 38 & 13.76 \\
\hline
\end{tabular}


Table 3: Distribution of attitude of respondent about dengue and malaria

\begin{tabular}{lccc} 
& Variables & Numbers & Percentage \\
1.Do you think you are at risk of & Yes & 181 & 65.57 \\
Disease & No & 31 & 11.23 \\
& Do not know. & 64 & 23.18 \\
2.Do you think clearing water & Yes & 221 & 80.07 \\
container weekly prevent & No & 13 & 04.71 \\
breeding & Do not know & 42 & 15.21 \\
& Individual / Family & 86 & 31.15 \\
3.Who you think responsible for & Community. & 44 & 15.94 \\
control activities of Disease & Local administration & 8 & 02.89 \\
& Municipality/ Nigam & 14 & 05.07 \\
4.Should Public Health & All of above & 124 & 44.92 \\
Personnel be allowed to spray & Yes & 153 & 55.43 \\
and inspect for vector control & No & 70 & 25.36 \\
5.Do you think sleeping under & Do not know. & 53 & 19.20 \\
net prevents Disease & Yes & 151 & 54.71 \\
6.Do you think to visit health & No & 58 & 21.01 \\
institution when suffering from & Do not know & 67 & 24.27 \\
high fever & Yes & 221 & 80.07 \\
\hline
\end{tabular}

Table 4: Distribution of practices of respondents about dengue and malaria

\begin{tabular}{lccc}
\hline & Variables & Numbers & Percentage \\
1. Environment cleaning can & Yes & 231 & 83.69 \\
prevent Dis. & No & 7 & 02.53 \\
& Do not know & 38 & 13.76 \\
2. How often you dry coolers & Every 3 ${ }^{r d}$ day & 35 & 12.68 \\
and containers of water. & Every $7^{\text {th }}$ day & 57 & 20.60 \\
& Every 14 ${ }^{\text {th }}$ day & 81 & 29.04 \\
& When empty after use & 104 & 37.68 \\
3. What preventive measure & Using bed nets & 101 & 36.59 \\
using & Using repellants/coils/liquids & 26 & 09.42 \\
& Wearing protective cloths & 17.77 \\
Using window, door screening & 49 & 03.98 \\
4. Overhead tank & Using chemoprophylaxis & 11 & 00 \\
5. How you dispose coconut & Nothing & 00 & 32.24 \\
shell, egg shell, empty & Covered & 89 & 87.31 \\
containers, tiers etc & Uncovered & 241 & 12.68 \\
6. How you dispose your used & Personnel or public dustbin & 35 & 61.95 \\
water & Outside open drain & 171 & 13.04 \\
& Septic tank & 36 & 25.00 \\
\hline
\end{tabular}




\section{Discussion}

As depicted in Table 1 . In the present study $66.66 \%$ were male participants and $33.33 \%$ were female participants in our study. From age group 15-25 years $9.78 \%$, from age group 26-35 years $15.21 \%$, from age group $36-45$ years $22.10 \%$ and from age group $46-60$ years $16.66 \%$ were the participants in present study. Among study group $97.46 \%$ were Hindu and $02.54 \%$ were Muslims by religion. As regard education status of participants, $43.84 \%$ were illiterate, $27.89 \%$ up to primary educated, $18.47 \%$ up to middle educated and $09.78 \%$ were up to secondary and above educated. In this study as regard their occupation $80.07 \%$ were farmers, $14.13 \%$ were engaged in some government or private service and $05.79 \%$ were doing business. 27.53\% participants were residing in Pacca houses, $54.71 \%$ were residing in semi-pacca houses and $17.75 \%$ were residing in kacha houses in present study. $14.13 \%$ of participants were from BPL class in present study.

As Table 2 depicts, while assessing the knowledge of participants it was found that $85.87 \%$ of participants heard about Malaria and Dengue while $14.13 \%$ participants did not heard about these diseases. In study of Debayan et $\mathrm{al}^{8}$ all respondent were aware of the disease. In a study by Charu Kohli et $\mathrm{al}^{9} 65.1 \%$ of respondent were knowing about Malaria and $62.3 \%$ respondent about Dengue. in Delhi. $38.76 \%$ of participant were knowing fever with chills and rigor, 09.78\% knew Headache / Body ache, 05.07\% knew Vomiting-Diarrhea as a symptom of these diseases and $46.37 \%$ of participants knew that all of the above were the symptoms of these diseases in our present study. Vikas et $\mathrm{al}^{10}$ in their study found that $75 \%$ of participant were knowing symptoms of these diseases. Debayan et al. reported that $80.2 \%$ of respondent knew fever as a symptom of these diseses. $28.1 \%$ of respondent in study of Charu Kohli et al, at Delhi were knowing about all symptoms of Malaria and Dengue. As regard transmission of disease $83.69 \%$ participants know that it is transmitted by mosquito bite, $03.98 \%$ were of opinion that it is transmitted by polluted air, $10.86 \%$ were of opinion that it is transmitted by ingestion of infected food and water and direct contact was attributed by $01.44 \%$ of participant as a cause of transmission in present study in a study by Yerpude PN et $\mathrm{al}^{11}$ from Andhra Pradesh, India found in his study that $70.09 \%$ of study population had awareness that mosquito bite is the cause for malaria but only $33.72 \%$ of the study population knew that Dengue, was transmitted by mosquito. Pandit $\mathrm{N}$ et al ${ }^{12}$ of Vadodara, Gujarat, in his study found that almost $71 \%$ of study population had awareness that mosquito bite is the cause for malaria but only $39 \%$ of the study population knew that dengue, is transmitted by mosquito. ${ }^{12}$ Vikas et al. in their KAP study found more than 90\% were knowing that it is transmitted by mosquito bite, so over all knowledge of transmission was good of Malaria as compared to Dengue which was lagging behind in IEC. As regard breeding site of mosquito, $79.71 \%$ know water as site, $07.60 \%$ Garbage as site, $03.26 \%$ soil as site and $02.53 \%$ Plants as a site for breeding and $06.88 \%$ do not know about the site of breeding of mosquito in present study. Similar were the observations in a study by Yerpude PN et al.from Andhra Pradesh, that $91.50 \%$ of the study participants had awareness about breeding places of mosquito. 22.29\% of study population still had myths that garbage was the breeding place for mosquito. Pandit $\mathrm{N}$ et al. in his study in Vadodara showed that $98.7 \%$ of the study participants had awareness about breeding places of mosquito. Boratne AV et al. ${ }^{13}$ in his study in Puducherry found that $59.79 \%$ male and $61.06 \%$ female respondents knew that stagnant water was the breeding place for vectors followed by ditches and ponds in the vicinity. In a study by Mayur $\mathrm{V}$ et al. ${ }^{14}$ among people of urban and rural areas of Rajkot district found that water collection was widely accepted as mosquito breeding place $(90.05 \%)$, among them around $(52.55 \%)$ respondents told ditches as mosquito breeding place and $(6.25 \%)$ respondents did not know about mosquito breeding places. Anand $\mathrm{T}$ et al. ${ }^{15}$ in his study conducted in a resettlement colony of central Delhi found that majority of the participants $(68 \%)$ knew about the breeding site of anopheles and Dengue mosquito. $92.39 \%$ of participants were not able to identify the mosquito responsible for these diseases, only $07.60 \%$ of participant could identify mosquito responsible for transmission of these diseases in present study. In the study of Debayan Poddar et al $7.3 \%$ could identify vector of malaria and $23.3 \%$ of respondent could identify vector of Dengue. Collection of water as a site for breeding of mosquito was a well-known feature in our study. $82.24 \%$ of participants held water logging as a cause of mosquito breeding while $03.98 \%$ were not of this opinion and $13.76 \%$ said they do not know about this in present study but in Debayan Poddar study 34\% of respondent regarded water logging as a cause of these diseases. In study of Charu Kohli et al at Delhi $49.7 \%$ of respondent knew that prevention of stagnation of water will prevent Malaria and Dengue.

As depicted in Table 3, while assessing attitude of participant, it was found that $65.57 \%$ of participant thought that they were at risk of these diseases while $11.23 \%$ thought no risk of these diseases and $23.18 \%$ were having no opinion on inquiring. Similar were the observation of Debayan who reported that $67.7 \%$ of participant felt that they are at risk of these diseases. $80.07 \%$ participant thought that clearing water container weekly will prevent breeding of mosquitos. $04.72 \%$ participants thought no while $15.21 \%$ participants were having no idea about it in present study. While assessing responsibility of control activities of these diseases, $31.15 \%$ thought individual / family is responsible, $15.94 \%$ participant thought community is responsible, $02.89 \%$ thought local administration is responsible, $05.07 \%$ thought municipality / nigam is responsible and $44.92 \%$ 
thought all of above are to be responsible in present study. Debayan et al. in their study reported that $25.3 \%$ respondent think that vector control is the responsibilities of municipality. Should Public health personnel be allowed to inspect and spray houses, $55.44 \%$ were of in opinion yes, $25.36 \%$ were of in opinion no and $19.20 \%$ had no opinion about it in our study. $54.72 \%$ participant thought sleeping under net will prevent these diseases, $21.01 \%$ participant thought no it will not prevent occurrence of these diseases, $24.27 \%$ do not have any opinion about this, in our study. $80.08 \%$ participants thought to visit health institution while suffering from high fever, $14.85 \%$ of participant thought no need to go to health institution and relied upon traditional household remedies like consuming lemon water, kadha of Tulsi, black paper etc or simply cold sponging. $05.07 \%$ participants had no opinion about this, in our study.

As depicted in Table 4. Assessing the practice, $83.69 \%$ of participants were of opinion that cleaning of environment will prevent occurrence of Dengue Malaria, $02.54 \%$ have negative opinion while $13.76 \%$ have no idea about it among respondents. $12.68 \%$ were drying coolers and containers of water every $3^{\text {rd }}$ day, $20.60 \%$ every $7^{\text {th }}$ day, $29.04 \%$ every $14^{\text {th }}$ day and $37.68 \%$ participants were drying only when it was empty after use in present study. On inquiring about use of protective measures $36.59 \%$ of participants were using bed nets, $09.42 \%$ were using repellents, coils or liquids, $17.77 \%$ were using protective clothing covering body, $03.98 \%$ of participants relied on screening of doors and windows and $32.24 \%$ used no preventive measure for prevention of Dengue and Malaria. In Dabayan study $7 \%$ respondent were using door -window screening for protection from mosquito and $53.8 \%$ were using mosquito repellents. $87.31 \%$ participants were using covered overhead tanks whereas $12.69 \%$ were using uncovered overhead tanks for their routine use in our study. In study of Charu Kohli et al at Delhi $41.1 \%$ of respondent were aware that covering of water containers will prevent Malaria and Dengue. On inquiring about disposal of coconut shells, eggs shells, empty containers and tiers etc $61.95 \%$ participants were throwing indiscreetly outside house, $13.05 \%$ were throwing on roof creating sites for breeding of mosquitos and $25 \%$ were using personal or public dustbins for disposal in present study. $76.44 \%$ of participants disposed their household used water outside in open drains, $06.88 \%$ participants used septic tank for disposal and $16.68 \%$ used street drains for disposal of used water in our study, showing their irresponsible behavior in this respect.

\section{Conclusion}

Rapid unplanned urbanization with the growth of substandard housing conditions, poor sanitation, and other anthropogenic environmental changes has made rural areas and urban slums more vulnerable to these diseases and unavailability of effective vaccines, resistance to anti-malarial and anti-dengue medicines has further worsen to the situation. Poor health education and poverty have further added to it. For tackling the situation community involvement and ownership are crucial for success and sustainability of VBD control program. For that we require to know local community perspectives and to identify the gaps and design culturally appropriate, effective malaria and dengue prevention, and control strategies looking to local situation. For this problem public health experts require a deeper insights into existing community perceptions and practices and thereby helps in identifying the attributes that influence the community in adopting healthy practices and responsive behaviors, as regard Malaria and Dengue.

\section{Source of Funding}

None.

\section{Conflict of Interest}

The authors declare no conflict of interest.

\section{References}

1. World Health Organization. Vector Borne Diseases. World Health Organization; 2017. Available from: http://www.who.int/newsroom/ factsheets/detail/vectorbornediseases.

2. World Health Organization. World Malaria Report 2018. World Health Organization. Available from: https://www.who.int/malaria/ publications/World.

3. World Health Organization. Neglected Tropical Diseases. Dengue. World Health Organization. Available from: http://www.searo.who. int/entity/vector_borne_tropical_diseases.

4. World Health Organization. National Framework for Malaria Elimination in India. 2016-2030. World Health Organization; 2016. Available from: https://apps.who.int/iris/handle/10665/246096.

5. Disease Control Programme. Annual Report of Department of Health and Family Welfare 2016-17. Available from: www.mohfw.nic.in.

6. Sahoo SK, Taraphdar P, Mallick AK, Dasgupta A, Preeti PS, Biswas D. How aware are we regarding vector borne diseases? A community based study in a slum of Kolkata, India. Int J Res Med Sci. 2017;5(6):2629-35. 001:10.18203/2320-6012.1]rms20172460

7. Podder D, Paul B, Dasgupta A, Bandyopadhyay L, Pal A, Roy S. Community perception and risk reduction practices toward malaria and dengue: A mixed-method study in slums of Chetla, Kolkata. Indian J Public Health. 2019;63(3):178-85. do1:10.4103/1]ph.1]ph_321_19.

8. Podder D, Paul B, Dasgupta A, Bandyopadhyay L, Pal A, Roy S. Community perception and risk reduction practices toward malaria and dengue: A mixed-method study in slums of Chetla, Kolkata. Indian J Public Health. 2019;63(3):178-85. doi:10.4103/1iph.IJPH_321_19.

9. Kohli C, Kumar R, Meena GS, Singh MM, Ingle GK. A study on knowledge and preventive Practices about mosquito bornediseases in Delhi. A Study on Knowledge and Preventive Practices about Mosquito Borne Diseases in Delhi MAMC. J Med Sci. 2015;1:169

10. Rathi A, Kumar V, Lal P, Goel SK. Malaria and dengue: Knowledge, attitude, practice, and effect of sensitization workshop among school teachers as health educators. J Fam Med Prim Care. 2018;7:1368-74. do1:10.4103/]fmpc.jtmpc_184_18

11. Yerpude PN, Jogdand KS, Jogdand M. A Study on awareness and practice about preventive methods against mosquito bite among 
households in an urban slum area of South India. Int J Rec Trends Sci Tech. 2013;1(8):69-71.

12. Pandit N, Patel Y, Bhavsar B. Awareness and practice about preventive method against mosquito bite in Gujarat. Heal J Indian Asso Prev Soc Med. 2010;1(1):16-20.

13. Boratne AV, Jayanthi V, Datta SS, Singh Z, Senthilvel V, Joice YS. Predictors of knowledge of selected mosquito-borne diseases among adults of selected peri-urban areas of Puducherry. J Vector Borne Dis. 2010;47(4):249.

14. Mayur V, Umed P, Nirav J, Dipesh Z, Chirag B, Ankit V. Awareness and Practices regarding commonly occurring mosquito borne diseases among people of urban and rural areas of Rajkot District, Gujarat. $J$ Res Med Dent Sci. 2013;1(2):46-51.

15. Anand T, Kumar R, Saini V, Meena G, Ingle G. Awareness and use of personal protective measures against mosquito borne diseases in a resettlement colony of Delhi. Ann Med Health Sci Res. 2014;4(2):227_ 32 .

\section{Author biography}

Surendra Mohan Mathur, Associate Professor

Brajesh Kumar, Assistant Professor

Rekha Mathur, Retired Senior Medical Officer

Ranjit K Jha, Professor and Head

Cite this article: Mathur SM, Kumar B, Mathur R, Jha RK. A study on community perception and risk reduction practices for dengue and malaria in field practice area of RHTC of JNUIMSRC, Jaipur- A cross-sectional study. Indian J Forensic Community Med 2020;7(4):196-202. 